\title{
Cutting teeth on translation technology: How students at University College London are being trained to become tomorrow's translators ${ }^{1,2}$
}

Mark Shuttleworth*

\section{Introduction}

Since the middle of the 1990s students on Masters courses in an increasing number of universities worldwide have been receiving training in the use of translation technology. Starting with perhaps half a dozen pioneer institutions world-wide, the practice has grown to such an extent that in many regions it is considered to be a near-essential part of any taught postgraduate degree (see Byrne 2007, Conclusions, for example).

Back in the 1990s, the market in translation memory (TM) was largely dominated by IBM TranslationManager and TRADOS Workbench (as it was then called). While the latest version of the latter still features largely in modern curricula, these also frequently take in some topics that could only be dreamt of back then: not only how to exploit free, reasonably accurate on-line machine

\footnotetext{
${ }^{1}$ This article is based on a presentation that I gave on 5 June 2016 as part of the ABRATES VII conference in Rio de Janeiro, the slides for which can be downloaded from my Academia.edu page at https://ucl.academia.edu/MarkShuttleworth/

2 I wish to express my thanks to Dr Lucas Nunes Vieira of the University of Bristol for kindly translating the title and abstract into Portuguese.

${ }^{*}$ University College London.
} 
translation (MT), but also the possibility of building your own MT engine from scratch.

The article aims to present two modules that I designed and have taught for the last three years. These are naturally not framed as the only way to approach the topic but rather as one possible implementation. Within the Masters programme of which they form a part, the modules serve as a broadbased, generic introduction to translation technology. Chan argues that academic institutions are 'possibly the best places to acquire the knowledge and skills of computer-aided translation' (2010a:85) because of the opportunity that they offer to combine in-depth study with practical experience from internships or 'projects in a real-life setting' (2010a:86). This is certainly a powerful reason for holding this view, and over the years a body of expertise has been developing that reflects a determination to be always aiming to improve what we provide for our students, as can be seen in publications such as Pym, Perekrestenko \& Starink (2006), Chan (2010b) and Bowker (2015). I also have written on the subject a number of times over the years (for example, Shuttleworth, Clark \& Rothwell, 2002; Shuttleworth, 2002, 2010).

\subsection{Technology skills within a broader picture}

Given the way in which this topic has come to feature so prominently in translator training curricula over the years, it should be no surprise to discover that it has been the subject of a number of international benchmarks and standards. One of the earliest of these was the product of LETRAC (Language Engineering for Translator Curricula: LETRAC, n.d.), a project that was active during 1998-9 and involved eight partners, all based in EU countries. This has long been superseded by new initiatives such as the European Masters in Translation. Their document on competences (Gambier, 2009) identifies the technological as one of the five essential skills areas that facilitate the sixth area,

which concerns the provision of translation services at a professional level, as shown in Figure 1: 


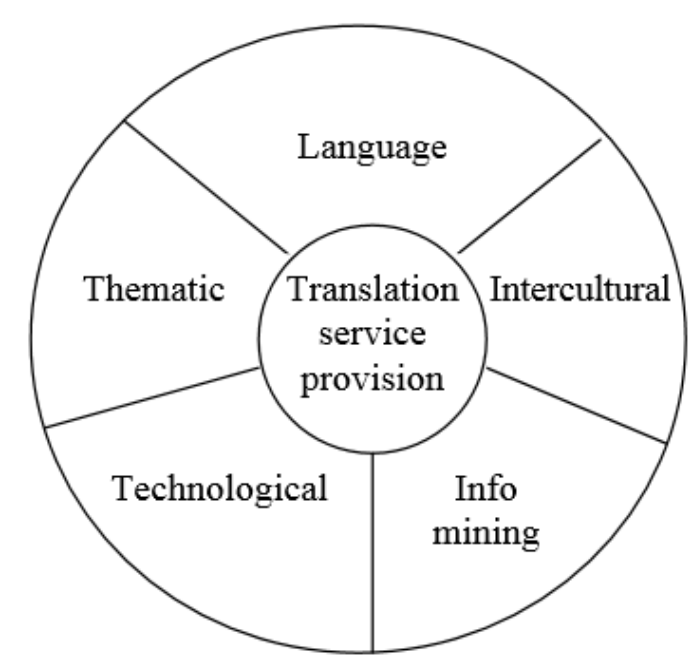

Figure 1: How the six competence areas relate to each other (Gambier 2009:4)

The technological competence gets broken down into a series of technical skills and attitudes that include the ability to use a range of software and the capacity to learn how to work with a new tool quickly and efficiently (2009:7). It is on ideas such as these that the modules' curriculum and approach are broadly based.

\section{Translation technology at University College London}

The use of translation technology has been taught at UCL since 2013, partly through the two modules 'Understanding and using Translation Technology' I and II, which are optional components of the MA in Translation Theory and Practice. Each year these modules typically attract a dozen or more students who form a group that is highly heterogeneous in terms of the language pairs in which they specialise, and the attempt is made to make the course content as neutral as possible between native and non-native speakers of English (who generally outnumber the native speakers in the group) so that nobody is disadvantaged because of their language background. Each module is taught via ten weekly two-hour sessions in a dedicated computer cluster, these taking the form of practical classes, but also with a limited number of lectures. Given 
the relatively small size of the group it is possible to deliver the module content without the need for teaching assistants. All the course materials are made available to students via the Moodle virtual learning environment. While the two modules are separate from each other most students enrol for both of them. Translation technology is also taught on the MSc in Specialised Translation, although the approach followed is somewhat different. Software for the modules is provided, often free of charge, by the producers, with whom we maintain good relations.

In the space of twenty weeks the modules aim to turn students - most of whom will at the outset be almost totally unfamiliar with the course content into burgeoning professionals who have the confidence to handle a number of roles in the translation industry, such as translator, project manager, terminologist and so on. We attempt to achieve this by equipping students to understand and use a wide range of technologies, ensuring at the same time that this practical ability is underpinned by a theoretical understanding of the technology.

In what follows I will be discussing the content of the modules and will then focus on three practical projects that either form part of this content or, in the case of the third, provide an adjunct to it. Each of these reflects one or more of the modules' key emphases: ensuring relevance to the professional realities of work in the translation industry; encouraging learning through completing tasks and solving problems; facilitating collaboration with classmates through teamwork; and developing partnerships within the College with the aim of generating translation projects that are both authentic and of practical benefit. Throughout the discussion, problems and challenges such as the following will be examined as and when they present themselves:

- managing the diverse backgrounds of the group members in the teaching context

- including both theory and practice in the curriculum 
- finding the right balance between TM and MT and deciding how many TM tools to include

- coping with the problem of small TMs

- understanding the professional roles within the translation industry that we are preparing our students for

- incorporating the Mac, which is the system that many of our students prefer to use

Other more generic IT skills such as file management and the use of Excel are assumed although remedial help would be available if need be.

\section{The technologies that we cover}

At the present time, translation technology is undergoing a process of significant reconfiguration - both the individual technologies and also how they interact with each other. And indeed, expert users frequently combine different types of technology in a fluid, flexible manner while working on a single project. We therefore consider it important to include a wide range of different types of software, and cover the following areas over the course of the two terms:

- terminology work

- translation memory

- machine translation and post-editing

- parallel text acquisition

- tool evaluation

- building an MT engine

All in all, however, we probably still devote a large proportion of the modules to translation memory. This is because, in spite of the shift away from workflows that are exclusively based around this technology and the merging of TM and MT that the last decade has witnessed, it is probably still the technology that most professional translators have most contact with, and this situation is likely to remain unchanged for the foreseeable future. As each new type of software is 
introduced students are encouraged to start putting it into practice straightaway not only with sample texts but also in translation assignments elsewhere in the programme. This is useful not only in view of the practical experience it provides but also because right from the start it allows students to begin to build up their own resources of reusable content.

Some may criticise the modules for not covering any one tool in great detail, and if this is true it is because we value breadth of understanding of how a technology works and what its potential is more highly than advanced skills in one particular system, which can in any case be acquired quickly and easily through use or via work-based training.

For the most part, the theory content is tied in with and supports the practical side of the module; there is thus a formal introduction to translation technology as well as lectures on terminology, current TM technology, research issues in TM, statistical machine translation (SMT) and evaluation of MT and TM systems. Reading assignments are also given in most but not all weeks.

The content that relates to each of the broad areas of translation technology that are listed above will now be discussed in what follows.

\subsection{Terminology work}

This component focuses firstly on locating and exploiting existing on-line resources such as the sizeable databases provided by the EU and the UN. Following that we cover active searching for relevant glossaries and individual terms using the Google search engine as well as the extensive resources available on translator networking sites such as Proz.com. After that, terminology management also features when we study TM tools and - along with terminology extraction, which we cover during the second term - as part of the MT engine building project described in Section 5. The collaborative project at the end of the first module also gives some participants the opportunity to put what they have learnt to practical use (see Section 4). 


\subsection{Translation memory}

Broadly speaking, there are two general approaches to teaching translation memory: focusing on one system - which in most cases will be the de facto industry standard SDL Trados Studio - and aiming to make the students expert users in it, or attempting to ensure that your students gain a broad understanding of how the technology works through exposure to several different systems (or indeed a middle course between the two). The methodology pursued in these modules favours the latter. By the time our students complete the second module they will be competent users of three TM tools: Wordfast Anywhere (https://www.freetm.com/), memoQ (http://www.memoq.com/) and SDL Trados Studio (http://www.sdl.com/solution/language/translation-productivity/trados-

studio/). One of the main justifications for this approach is that, while different systems possess the same basic functionality, each offers different and sometimes innovative features in terms of how the TM and other resources are exploited. In addition, this approach is also inspired by the belief that it facilitates the development of a person's ability to learn (or evaluate) a new tool quickly and efficiently.

While all students starting these modules are highly likely to be at least slightly acquainted with MT, the concept of TM will be new for nearly all of them. In the past, when the two technologies were quite distinct and the use of MT was largely confined to large corporations and organisations such as the military, the task of teaching students about TM was arguably simpler, at least in the early stages: broadly speaking, while an MT system did the translating for you, in TM the translator remained in control. Now, however, the convergence of these technologies that the last few years have brought gives rise to potential confusion almost immediately: by default, some TM tools now serve up machine-translated versions of sentences for which there is no match in the TM, which immediately challenges the basic distinction that I have just described. 


\subsection{Machine Translation and post-editing}

It is only with this merging of technologies that a greater place has been made for MT within our curriculum. That said, we do not use a locally installed MT system. This is partly because it is not possible to guarantee that all the language pairs that are needed will be available; Google Translate, on the other hand, is able to translate between 104 languages (at the time of writing). Consequently, we focus on the following systems and topics:

- Google Translate (https://translate.google.com/)

- Google Translator Toolkit (https://translate.google.com/toolkit/)

- how the use of on-line MT is implemented within TM tools

- the practicalities of post-editing within each of these systems and beyond

- how SMT works

The fact is that we can cover most of what we need to with on-line TM (although including a configurable system such as Systran would be a useful addition), while the notion of training a system with your own content is introduced in the KantanMT project that is described in Section 5. The decision to focus on on-line systems is also not entirely unconnected with the question of cost, it has to be said. It is of course unfortunate that the use of most MT engines in conjunction with a TM tool is now a chargeable service, although some tools (e.g. Wordfast Anywhere) still provide the possibility of connecting to at least one free service that produces translations of reasonable quality.

From the point that our (brief) coverage of Google Translate takes place onwards, post-editing becomes an unmoveable feature of much of our work. Students are exposed to a variety of interfaces and are made aware that the thoroughness of the clean-up will need to reflect the purpose that the translation is intended to serve.

\subsection{Parallel text acquisition}

This is an item that has only been included relatively recently. We were aware of an inconsistency between our attempts to convince students that TM only 
becomes of real value when you are able to work with sizeable memories and the fact that within the context of these modules there has been no time for large databases to develop. This is a common problem in courses such as this that take place over a matter of weeks or months and that permit students only relatively limited time working with the software, and even though they are encouraged to transfer their resources whenever we move to a new tool this only goes a certain way towards solving it.

One possible solution would be to archive students' TMs and make them available from one year to the next, and although I understand that this has been implemented in some institutions it is not an approach that we have pursued at this stage. What we decided was that it would be useful to show students how to download sizeable chunks of bilingual aligned data and import them into their TM tool. This allows them get the experience of working with a large TM, even if it is not possible to guarantee that the data imported is directly relevant to the text they are translating in view of the relatively limited nature of what is available on-line. We therefore introduce the students to a number of resources including MyMemory (https://mymemory.translated.net/) and the repositories at OPUS (http://opus.lingfil.uu.se/: see Figure 2) and TAUS (https://www.tausdata.org/), the first of which is freely available and the second accessible to staff and students under the TAUS Academic Membership scheme, and both of which permit you to select and download relevant aligned text. An additional benefit of this is that students become acquainted with the TMX (Translation Memory eXchange) file format, which is an important component of TM technology.

\begin{tabular}{|c|c|c|c|c|c|c|c|c|}
\hline corpus & doc's & sent's & src tokens & trg tokens & XCES/XML & raw & TMX & Moses \\
\hline GNOME & 1873 & $0.7 \mathrm{M}$ & $4.0 \mathrm{M}$ & $4.6 \mathrm{M}$ & [xces en pt_BR & [en pt_BR] & [tmx ] & [moses] \\
\hline KDE4 & 2163 & $0.2 \mathrm{M}$ & $2.4 \mathrm{M}$ & $2.6 \mathrm{M}$ & [xces en pt_BR] & [en pt_BR] & [tmx ] & [moses ] \\
\hline Ubuntu & 452 & $0.2 \mathrm{M}$ & $0.8 \mathrm{M}$ & $0.7 \mathrm{M}$ & [xces en pt_BR] & [en pt_BR] & [tmx ] & [moses ] \\
\hline PHP & 3281 & $40.4 \mathrm{k}$ & $0.5 \mathrm{M}$ & $0.2 \mathrm{M}$ & [xces en pt_BR] & [en pt_BR] & [ $\operatorname{tmx}$ ] & [moses] \\
\hline total & 7769 & $1.1 \mathrm{M}$ & $7.8 \mathrm{M}$ & $8.0 \mathrm{M}$ & $\overline{1} .1 \mathrm{M}$ & & $0.2 \mathrm{M}$ & $0.3 \mathrm{M}$ \\
\hline
\end{tabular}

Figure 2: A list of parallel text collections for English $<$ Brazilian Portuguese available for download from the OPUS site 


\subsection{Tool evaluation}

In the single session devoted to this we cover approaches to MT evaluation that involve both human judgement and the use of automatic metrics, focusing in the case of the latter on BLEU (which is what is used in the KantanMT project). We also explore a number of measures for evaluating TM systems, including those suggested by EAGLES (1995).

\subsection{Building an MT engine}

This is described in detail in Section 5.

\section{The collaborative translation project}

The practice of including simulated projects as part of translation technology training is well established, having for example been implemented in the University of Leeds in the late 1990s, and is now believed to be relatively widespread in the UK and beyond. The Chinese University of Hong Kong's MA in Computer-Aided Translation, for example, includes an entire module devoted to a technology-assisted translation project (see Chan, 2010a). The translation project run from the University of East Anglia is also described in detail by Drugan (2015); interestingly, the specification used there includes collaboration with three other institutions, the University of Essex, the University of Geneva and York University, Toronto, based in three different time-zones (Drugan, 2016). The University of Swansea has also run a project of this kind for a number of years (Rothwell, 2012).

UCL is somewhat remarkable for the fact that it houses three major public museums on or near its main campus. Not least among these is the Grant Museum of Zoology, a repository of some 68,000 specimens. Since collaboration with different bodies within our institution is something that we consider to be worthwhile, for the last two years we have been working together with them to produce translations of some of the on-line documentation that describes their collections. This collaboration takes the form of a team-based, collaborative 
project - one of a series that we have included in our modules, both at UCL and previously at Imperial College and Leeds.

Coming at the end of the first term, this annual collaborative project sees the students divided into several teams, each with around half a dozen members. The teams are issued with a detailed project specification including precise instructions on what to translate, role allocations (with full descriptions of each role) and information on the deadlines. The choice of what technology to use is left entirely to each team, as are decisions regarding the procedures and workflows that will be followed.

The roles that each person is assigned to within their team include translator, terminologist and project manager. Where possible, the teams are mixed in terms of the members' target language, and all project managers have in their team at least one language with which they are unfamiliar. Each team is tasked with translating a set of documentation, which has most recently consisted of the Museum's introductory 'Top Ten Objects' publicity document along with other materials, the precise quantity depending on the number of team members specialising in a particular target language. To facilitate the realtime sharing of terminology and TMs - which is always an issue on projects such as this, where many people will be working remotely for much of the time during last year's project a server was kindly made available by Kilgray, the developers of memoQ, and we decided to make it part of the learning experience to allow the teams to try to get to grips with it with no formal guidance from ourselves. A strict deadline is always imposed, even if by the standards of the industry the time allowed may be seen as generous: after all, the participants are students rather than experienced professionals, and we want them to have the time to discuss the procedures, to get used to the roles, and to reflect on and learn from what they are doing. The final three sessions of the first module are exclusively devoted to work on the project to facilitate face-to-face networking and the provision of guidance. The project is assessed, with translations, team files and individual reports being submitted after completion of the practical part of the project, followed in due course by a reflective report. 
Without exception, the students rise to the occasion and work hard to ensure that their assignment is completed on time and to a high standard. A flavour of how useful the last year's project appears to have been as a learning experience can be obtained by reading some of the written feedback of our project managers, who needless to say are the ones who bear the brunt of the planning and organisation:

- 'All in all, our project proceeded very well and I am proud of our work and my teammates.'

- 'The language barrier between me and the rest of the team was at times challenging. I had to remind them to speak English, so as not to be left out of the conversation that I essentially had to make a decision upon.'

- 'Conclusively, we made the best of the resources available to us: both our own personal expertise and the software at hand. What carried us through though was communication.'

- 'Software was merely the assistant in a top notch team effort.'

- 'It was a bit stressful to see that other groups quickly abandoned [the server] and shifted to other online services to exchange files and got head starts, but I decided that we should still spend some extra time on our exploration with the server since we still had enough time left for starting over again. Though there were some twists and turns, I managed to settle down the workflow.'

- 'My group members not only shared with me their discoveries, but also unswervingly supported my decisions. I want to extend my greatest gratitude to them at the end of this report.'

From these comments it should be clear that the project managers at least had a taste of the cut-and-thrust of working in a high-pressure professional context, although I believe that was almost certainly the case for all the other participants as well.

The original Top Ten Objects document along with last year's students' translations into Spanish and Simplified Chinese can be viewed at 
https://www.ucl.ac.uk/museums/zoology/about/collections/objects. Extracts from the first two of these can be seen in Figure 3:

TOP TEN Grant Museum of Zoology

OBJECTS

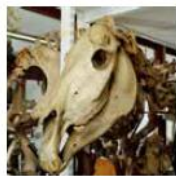

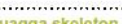

Extinct and Endangered' dispta

near museum entrance

There are only seven known examples of this

South African zebra, extinct since 1883

making this the rarest skeleton in the world.

'Extinct and Endangered' display

These dog-like carnivorous marsupials were

deliberately driven to extinction in 1936.

The Museum houses extremely rare

preserved dissections and skeletons.

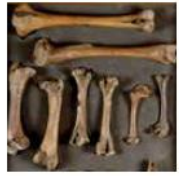

$$
\begin{aligned}
& \text { Dodo bones } \\
& \text { 'Extinct and Endangered' display } \\
& \text { near museum entrance } \\
& \text { These icons of extinction had disappeared } \\
& \text { by } 1681 \text {. The Grant Museum has a large }
\end{aligned}
$$
assemblage of bones.

Figure 3: Extract from the original English-language Top Ten Objects document and the version translated into Spanish by our students

\section{The MT engine building project}

A number of systems are now available that permit users without programming skills to create their own customised MT engines. Unlike the one just described, the project that takes place at the end of the second term is based on individual rather than team-based work. It is designed to draw on a number of the topics that have been introduced during the second module: alignment, term extraction, parallel text acquisition and MT evaluation.

SMT has been playing a part in some translation technology curricula for a number of years. MT in general, and SMT in particular, perhaps, are not without their points of controversy, and Kenny and Doherty argue for teaching strategies that encourage the empowering of translators through SMT rather than their marginalisation (Kenny \& Doherty, 2014:283-5). When it comes to implementation, these same authors provide a detailed discussion in another co-authored article (Doherty \& Kenny, 2014). 
For this project each student has to use the KantanMT on-line interface for creating MT engines (https://www.kantanmt.com/), for which for the last three years free temporary licences have been generously provided by the developers, in order to create and train their own SMT system. Even a few years ago such a task would have been unthinkable for anyone who did not possess the technical ability to install and operate the Moses SMT toolkit (http://www.statmt.org/moses/), whereas now it can all be accomplished via a user-friendly interface such as the one developed by KantanMT. As with the previous one, the last three sessions of the module are allocated to the project, and then the students continue working on it over the month-long Easter vacation. Work on the project entails a number of steps. The first is to choose a subject area (and select one or more test texts), with an eye of course to the need to be able to locate fairly significant amounts of relevant training data. Following this, using the interface an MT engine is created and a 'stock engine' - consisting of an initial quantity of training data relevant to a broad subject area for a specific language pair - is selected from a list (see Figure 4) and assigned to the new engine. After these two preliminary steps, most of the time is taken up with participants trying to improve the quality of the engine incrementally by adding resources to it; training data takes the form of a) extracted or otherwise acquired bilingual terminology resources, b) specially created relevant target language text corpora and c) parallel text resources that students have aligned or otherwise acquired. Of these, the third category is by far the most important, while the quantity and quality of the training material uploaded into the system determine the ability of the emerging MT engine to translate accurately. The students' final task is to track the BLEU score (as reported in the KantanMT interface). This itself constitutes a significant learning experience as the students quickly discover that new training material can cause the score to go down as well as up, depending on the extent to which it is focused on the selected subject area. 


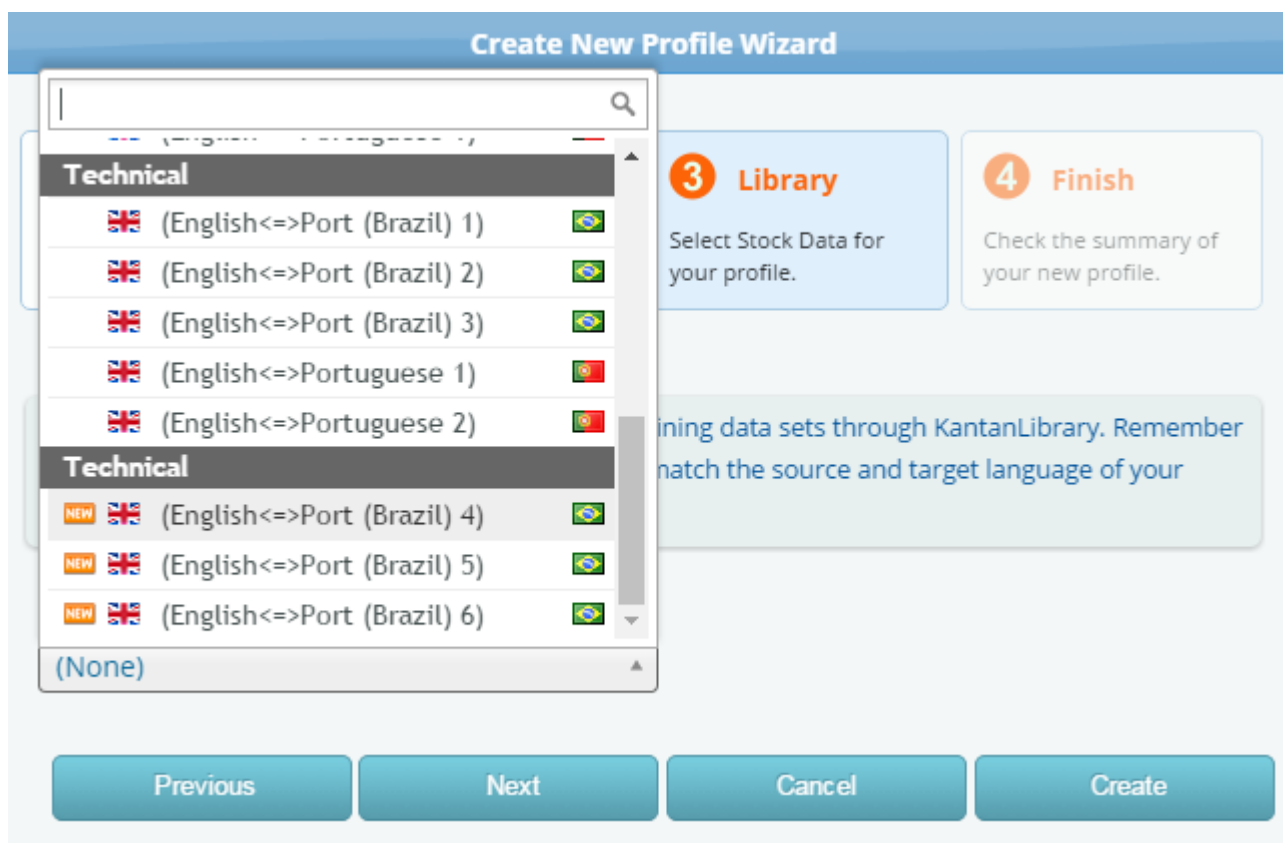

Figure 4: Selection of a stock engine for the English $<$ Brazilian Portuguese language pair

This is perhaps one of the most rewarding parts of the modules for us as we are delighted to see the energy and determination with which the students set about creating, collecting and uploading training material. Over the several weeks that are devoted to the project nearly all of them apply themselves to this task with great dedication and determination. As an illustration of what is possible, this last year one student uploaded twelve Wikipedia articles, $36 \mathrm{MB}$ of terminology in TBX format and 2 GB of aligned data in TMX format, corresponding to a total of nearly three million segments.

Once again, this project forms part of the module's assessment, on the basis of a reflective individual write-up and, to a much lesser extent, the final BLEU score achieved. 


\section{The TermSeeker project}

Last year, as an adjunct to the modules an opportunity arose to obtain modest funding for an e-learning development project the aim of which was to produce the plans for and develop a mobile app to search for glossaries on-line. This project, which bears the name 'TermSeeker' (https://termseeker.wordpress.com/, https://www.facebook.com/termseeker/), also benefited from a call from the UCL Department of Computer Science for app ideas for their students to develop. The project is still on-going although all the students originally involved have now graduated.

The TermSeeker app is designed to facilitate mono- and bilingual glossary searching in 64 languages through a combination of specific and preselected generic search terms. On a purely voluntary basis, ten participants in the modules took part in the project. The relevance of the project to the modules was clear and participants were highly motivated because of this; although only one member of the team had experience with software creation, the entire team engaged actively in planning, researching existing tools and thinking about design issues. While the immediate focus of the project was on the specifics of the app the team members also acquired the more generic skills of writing blog posts and wiki entries. Once the specification had been worked out by the team it was passed on to a pair of computer science students for implementation. It is hoped that an initial version for Android will be launched in due course.

\section{Has our training kept pace with reality?}

The above is an example of how it is possible to teach translation technology in a way that offers at least a reasonable reflection of the current state of the field and equips students for work in the translation industry with a broad understanding of how the technology functions. As I stated at the beginning, it is by no means the only possible approach to take. UCL's records indicate that most but not all of our graduates launch themselves on a career in the translation industry. The exact roles that they come to occupy either immediately after or within a few years of graduation include both freelance and in-house translator 
(including at FIFA and in the Prime Minister's office, for example), project manager, machine translation language specialist, lecturer, trainer and translation company owner. This alone would seem to suggest that our students possess at least some of the skills needed to ensure success in this professional field.

The demise of TM has been announced at regular intervals over the last few years, but at the time of writing it still seems to be alive and well as a working method used by freelancers and companies alike. In addition, when combined with MT and post-editing (for example) it becomes a vital tool for the generation of new parallel content, which can in turn be used as training data to improve the performance of MT engines. (Indeed at the level of big data this function seems to be gradually taking over as the main one.) Hence I consider that the substantial space that it continues to be given in our curriculum remains fully justified, even though the form in which it is used may well change over the next few years. On the other hand, it is true to say that curricula are in general probably needing to become increasingly MT-driven, and that translation technology is overall certainly not standing still: new and seemingly superior approaches such as neural MT and interactive, adaptive MT seem to be either impacting or even displacing SMT; great strides are being made in speechto-speech MT; and innovative TM tools (or features within long-established ones) continue to be introduced. Those responsible for curriculum development consequently have little chance of being able to rest on their laurels: curricula are constantly needing to evolve and courseware to be updated from one year to the next not only to reflect the latest software versions but to allow for the introduction of new tools whenever this seems to be called for.

That said, it seems to me that what is most important to impart to our students is a number of vital abilities and attitudes that they can take with them into their professional lives. These would include, but perhaps not be limited to the following: absorbing a range of different types of technology; adopting a flexible approach to technology; creating, capturing and redeploying content; learning new tools quickly and confidently; and knowing when not to use 
technology. All the regular features of the modules seek to further these aims, as indeed did the TermSeeker project that was included on a one-off basis when the opportunity presented itself in order to engage the students' interest in what I hoped would be a novel manner.

One important matter that this article has not been able to address is how potential trainers such as those planning to establish a course in translation technology in their own institution can themselves receive the training that they need to help them to face the challenges with which the implementation of their plans will present them. Besides presenting the content of the UCL modules the article has discussed problems and challenges that I see as either on-going or current. Most of those that were listed at the end of Section 2 have been addressed either directly or obliquely during the discussion. Many other challenges have had to be solved over the years, although as our know-how improves there will always be new ones to face. And I am still trying to work out what to do about the Mac...

\section{References}

BOWKER, Lynne. “Computer-aided translation: Translator training". In: Sinwai Chan (ed.), Routledge Encyclopedia of Translation Technology, London and New York: Routledge, p. 88-104, 2015.

BYRNE, Jody. "Translation and the Internet: Changing the face of an industry". In: Ian Kemble (ed.), Translation Technologies and Culture, Portsmouth: University of Portsmouth, p. 23-34, 2007. Available at:

http://www.jodybyrne.com/169 (accessed 9 February 2017)

CHAN, Sin-wai. "A new curriculum for the teaching of translation technology: The teaching of a translation project course as a case study". In: Sin-wai Chan (ed.), Journal of Translation Studies 13, 1\&2 Special Issue: 'The teaching of computer-aided translation', p. 83-154, 2010.

DOHERTY, Stephen \& KENNY, Dorothy. "The design and evaluation of a statistical machine translation syllabus for translation students", The Interpreter and Translator Trainer 8, 2, p. 295-315, 2014. Available at: 
http://dx.doi.org/10.1080/1750399X.2014.937571

DRUGAN, Joanna. "Issues for professional masters: Bringing the real world into the classroom". In: P. Kneale (ed.), Masters Level Teaching, Learning and Assessment: Issues in Design and Delivery, London: Palgrave, p. 158-70, 2015.

DRUGAN, Joanna. “Questioning professional practice in the CAT classroom”. Delivered at Symposium: Best practices, challenges and new horizons in the teaching of translation and translation technology, 23 September 2016, University of Surrey. Available at:

http://www.surrey.ac.uk/englishandlanguages/news_and_events/events/2016/ symposium_best_practices_challenges_and_new_horizons_in_the_teaching_of _translation_and_translation_technology.htm (accessed 8 February 2017)

EAGLES. Evaluation of Natural Language Processing Systems: Final report, 1995. Available at:

http://www.issco.unige.ch/en/research/projects/ewg95/ (accessed 8 February 2017).

GAMBIER, Yves (on behalf of the EMT Expert Group). "Competences for professional translators, experts in multilingual and multimedia communication", 2009. Available at: http://web.archive.org/web/20160916125047/http://ec.europa.eu/dgs/translatio n/programmes/emt/key_documents/emt_competences_translators_en.pdf (accessed 9 February 2017)

KENNY, Dorothy \& DOHERTY, Stephen. "Statistical machine translation in the translation curriculum: Overcoming obstacles and empowering translators". In The Interpreter and Translator Trainer 8, 2, p. 276-94, 2014. Available at:

http://dx.doi.org/10.1080/1750399X.2014.936112

LETRAC. Available at:

http://web.archive.org/web/20060106043254/http://www.iai.uni-

sb.de/iaide/en/letrac.htm (accessed 9 February 2017)

PYM, Anthony; PEREKRESTENKO, Alexander \& STARINK, Bram (eds.). Translation technology and its teaching, Tarragona: Servei de Publicacions, 2006. Available at: 
http://www.intercultural.urv.cat/media/upload/domain_317/arxius/Technolog y/translationtechnology.pdf (accessed 9 February 2017) ROTHWELL, Andrew. "WG 5 - Draft Template for Case Studies of good practice in translator training". 2012. Available at:

http://www.ressources.univ-rennes2.fr/service-relationsinternationales/optimale/attachments/article/15/WP5.1.\%20Case\%20study_Swa nsea_EN.pdf (accessed 1 February 2017) SHUTTLEWORTH, Mark, CLARK, Bob \& ROTHWELL, Andrew. "Integrating Language Technology into a Postgraduate Translation Programme". In: Proceedings of 'Training the Language Services Provider for the New Millennium' (III encontros de tradução da AstraFLUP), Porto: Faculdade de Letras, Universidade do Porto, p. 63-70, 2002.

SHUTTLEWORTH, Mark. "Combining MT and TM on a Technology-oriented Translation Masters: Aims and Perspectives". In: Proceedings of $6^{\text {th }}$ EAMT Workshop: Teaching Machine Translation (UMIST, Manchester), November 14-15 2002, Manchester, p. 123-129, 2002. Available at:

http://www.mt-archive.info/EAMT-2002-Shuttleworth.pdf $\quad$ (accessed 8 February 2017)

SHUTTLEWORTH, Mark. "Teaching localisation via e-learning: developing and delivering an e-course on software localisation at Imperial College London". In: Sin-wai Chan (ed.), Journal of Translation Studies 13, 1\&2. Special Issue: 'The teaching of computer-aided translation', p. 3-12, 2010.

\begin{abstract}
The article describes two translation technology modules available to MA students at UCL. These modules emphasise the following: combining theory and practice; preparation for the translation industry; use of the software in all practical translation work; teamwork; learning by doing and by participating in projects. They aim to cover a wide range of translation technology and technology-related topics, including terminology, translation memory, machine
\end{abstract}


translation, term extraction, system evaluation, parallel text acquisition and statistical MT engine training. Overall, their goal is to produce versatile problem-solvers rather than software users dependent on a particular system.

\section{Resumo}

Este artigo descreve duas disciplinas de tecnologia de tradução disponíveis para estudantes de mestrado na UCL. As disciplinas têm por base os seguintes aspectos: combinação de teoria e prática; preparo para a indústria de tradução; uso de software em todas as atividades práticas de tradução; trabalho em equipe; aprendizagem prática e por meio de projetos. As disciplinas têm por objetivo cobrir uma vasta gama de tecnologias de tradução e tópicos relacionados a tecnologia, como terminologia, memória de tradução, tradução automática, extração de termos, avaliação de sistemas, busca de textos paralelos e treinamento de sistemas estatísticos de tradução automática. Em geral, as disciplinas visam produzir 'resolvedores de problemas' versáteis em vez de usuários de um programa de computador específico. 